\title{
Epidemiological Studies on Relation between Streptococcus pneumoniae with Respiratory Diseases
}

\author{
A. Ismail ${ }^{1}$; M.M Bahgat ${ }^{1}$; M. Abdel-Raouf ${ }^{2}$ and M. A. Abd Allah*1 \\ ${ }^{1}$ Faculty of Science, Port Said University, Egypt. \\ ${ }^{2}$ Gastro - Enterology Center, Faculty of medicine, Mansoura University, Egypt.
}

Received: 29 Sept. 2016 /Accepted: 27 November 2016

*Corresponding author: mona_hanina@yahoo.com

\begin{abstract}
Streptococcus pneumoniae is the leading cause of bacterial infections worldwide and causes a range of illness from otitis media to pneumonia and meningitis.

The study was carried out in Mansoura university hospitals, Egypt over period of 12 month. On a number of 71 patients, all of them are suffering from respiratory tract diseases (Acute bronchitis, chronic obstructive pulmonary disease, Pneumonia, Chronic suppurative lung disease, bronchial asthma) their ages ranged from 15 -75 years. Results showed that Streptococcus pneumoniae bacteria that were isolated from sputum samples were (34\%), S. pneumoniae isolated from patients in Age $\leq 35$ was (17\%), and in age $\geq 35$ Streptococcus pneumoniae was (37.3\%). Streptococcus pneumoniae isolated from patients with chronic bronchitis was $25 \%$, while pneumonia was (50\%), while chronic obstructive pulmonary disease was $14.3 \%$, and chronic suppurative lung disease was (33.8\%). The sensitivity patterns proved that Streptococcus pneumoniae in antibiotic prepared disc is highly sensitive to Levofloxacin.
\end{abstract}

Keywords: Respiratory tract diseases, Streptococcus pneumoniae, Antibiotics.

\section{Introduction}

Respiratory tract infections (RTIs) are one of the major public health problems and a leading cause of morbidity and mortality in many developing countries. Respiratory tract is the most common site for infection by pathogens because it comes into direct contact with the physical environment and is exposed to microorganisms in the air. Streptococcus pneumoniae causes an acute bacterial infection. Bacteria isolated from respiratory tract infection were Staphylococcus aureus, Streptococcus pneumonia, Haemophilus influenzae, Pseudomonas aeruginosa, Klebsiella pneumoniae, and Moraxella subgenus Branhamella catarrhalis Goto $\mathrm{H}$; et al (2005). The common bacteria causing respiratory tract infections were Streptococcus pneumoniae has the highest percentage of occurrence, followed by Klebsiella pneumoniae, Escherichia coli (20.9\%) and Staphylococcus aureus, respectively. D. W. Taura, et al. (2013).

Streptococcus pneumoniae (pneumococcus) remains an important cause of pneumonia, meningitis, 
bacteremias, and acute otitis media worldwide. Antimicrobial resistance among pneumococci has escalated dramatically over the past three decades, and is influenced by patterns of antibiotic use, population density, and spread of a few international clones. Lynch JP 3rd, Zhanel GG.(2010).Each year, approximately half of the 2.6million deaths due to acute respiratory infections in children under five are due to pneumococcal pneumonia. Invasive pneumococcal disease (IPD, pneumonia, meningitis, and sepsis) in children is particularly associated with mortality and is a major cause of hospitalizations and long-term neurologic sequelae. Carla A. Talarico (2009)

Antibiotics are the mainstay of acterial treatment, the goal of these drugs is to kill the invading bacteria without harming the host Archer and Ronald, (2001). Antibiotic effectiveness depends on mechanism of action, drug distribution, site of infection, immune status of the host, and resistance factors of bacteria .Antibiotics work through several mechanisms. Some (such as vancomycin and penicillin) inhibit formation of bacterial cell walls. Erythromycin, tetracycline, and chloramphenicol interrupt protein synthesis. Still others inhibit bacterial metabolism (sulfa drugs) or interfere with DNA synthesis (ciprofloxacin, rifampin) and/or cell membrane permeability (polymyxin b) Conte JE, (2002). When antibiotics were discovered in the 1940s, they were incredibly effective in bacterial infection treatment. Over time, many antibiotics have lost effectiveness against common bacterial infections because of increasing drug resistance Perez et al., 1990; Barie, 1998; Domin, (1998). Bacteria may be naturally resistant to different classes of antibiotics or may acquire resistance from other bacteria through exchange of resistant genes. Indiscriminate, inappropriate, and prolonged use of antibiotics have selected out the most antibiotic-resistant bacteria Petrosillo and Pantosti, (2002). Antibioticresistant strains have emerged in hospitals, long-term care facilities, and communities world wide Levin and Levy, (2003).

The study was carried out in Mansoura university hospitals, Egypt over period of 12 month. on a number of 71patients (40males and 31 females) all of them are suffering from respiratory tract diseases (Acute bronchitis, chronic obstructive pulmonary disease, Pneumonia, Chronic suppurative lung disease, bronchial asthma) their ages ranged from 15 years to 75 years, , 38 patients nonsmoking and 33 patients smoking .Data entry was completed using Microsoft excel. SPSS Program and medical programs for statistical analysis (SPSS Inc., Chicago, IL, USA) was used for data analysis.

\section{Material and methods:}

The present study was conducted on a number of 71patients (males and females) were subjected to clinical examination in hospitals of Mansoura university, Egypt their ages ranged from 15years to 75 years, This study done over period of 12 months. In this study there are 40 male and 31 females all of them are suffering from respiratory tract diseases (Chronic bronchitis, chronic obstructive pulmonary disease, Pneumonia, Chronic suppurative lung disease). All patients were subjected to the history (Sex, Age and smoking habit), clinical examination and a complete physical examination including symptoms and signs indicating the development of bacterial infection.

\section{Sample collection:}

Sputum samples were collected in sterile plastic container under complete aseptic conditions, the best sample is the early morning sputum. The patient should expectorate from deep down in the lung. If patient failed to expectorate, sputum may be induced by expectorant or by inhalation of heated saline hypertonic first morning sputum sample was collected directly into a sterile wide mouthed container and transported to laboratory according to standard protocol (Cheesbrough. M. 2000).

\section{Preparation of sputum samples:}

Add to the sputum about $5 \mathrm{ml}$ of sterile physiological saline to obtain as pure a culture for isolation of streptococcus pneumoniae as possible of a respiratory 
pathogen it is necessary to reduce the number of commensal inoculated. (Cowan and Steel, 1974) and (Cheesbrough, 2000).

\section{Isolation and identification of bacterial strains:}

Isolation was performed using horse blood agar media (Oxoid), each Plate was inoculated by spreading aloobful of prepared sputum sample. Incubation of culture plate's media was placed in an inverted position for 24 to 48 hours at $37^{\circ} \mathrm{C}$. Isolates were identified according to colonial morphology and appearance, growth characteristics, hemolytic pattern, microscopically by Gram's stain and biochemically (Catalase test, Coagulase test, alpha hemolysis on blood agar media, Bile solubility test, Optochin susceptibility test) according to Bergey's Manual of Determinative Bacteriology (Holt etal., 1994)

\section{Antibiotic susceptibility testing}

Antibiotic susceptibility tests were performed using the disc diffusion method. Fourteen different antibiotics (Levofloxacin, Azithromycin, Meropenem, Ciprofloxacin, Gentamycin, Imipenem, Cefotaxime, Cloxacillin, and Amoxicillinlclavulanic acid, Ceftazidime, Spiramycin, Piperacillin, Ampicillin/sulbactam, and Ampicillin) were tested for determination of their antibiotic effects on the isolated strains.

\section{Statistical analysis}

All data were run on IBM compatible personal computer using the software Statical Package for Social Scientist (SPSS) Program and medical programs for statical analysis (SPSS Inc. Chicago, IL, USA).The trend $\mathrm{x}^{2}$ test for statistical comparisons between the groups and a $\mathrm{p} P$ $<0.05$ was considered as statistically significant.

\section{Results:}

Seventy one patients their ages ranged from 15 years to 75 years, 40 male and 31 females all of them are suffering from respiratory tract diseases (12 chronic bronchitis, 22 Pneumonia, 21 chronic obstructive pulmonary disease, 16 chronic suppurative lung disease), 38 patients non Smoking and 33 patients smoking.

The respiratory tract infections in Man were chronic bronchitis (9.8\%), Pneumonia (31.71\%), chronic obstructive lung disease (COPD) (26.83\%), chronic suppurative lung disease (CSLD) (31.71\%) While in woman were chronic bronchitis (13.33\%), Pneumonia (33.33\%), Chronic obstructive lung disease (COPD) (36.67\%), Chronic suppurative lung disease CSLD (16.67\%).

There was a significant relationship between the sex and the diagnosis of patients $\left(\mathrm{P}^{*}=0.01\right)$.

The respiratory tract infections in Age $\leq 35$ were chronic bronchitis $(25 \%)$, Pneumonia (50\%), chronic obstructive lung disease (COPD) (17\%) and chronic suppurative lung disease (CSLD) (8\%). While Age $\geq 35$ are chronic bronchitis (8\%), pneumonia (29\%), chronic obstructive lung disease (COPD) (34\%), chronic suppurative lung disease CSLD (29\%).

There was a significant relationship between the Age group and the diagnosis of patients $\left(\mathrm{P}^{*}=0.02\right)$.

The respiratory tract infections in Nonsmoking patients were chronic bronchitis $(15.8 \%)$, pneumonia $(39.5 \%)$, chronic obstructive lung disease (COPD) (31.5\%), and chronic suppurative lung disease (CSLD) (13.2\%), while Smoking patients are chronic bronchitis $(6.1 \%)$, Pneumonia (24.8\%), COPD $30.3 \%$, and Chronic suppurative lung disease (CSLD) (39.4\%).

There was a significant relationship between the smoking habit and the diagnosis of patients $\left(\mathrm{P}^{*}=0.0116\right)$.

Colonies of twenty four plates appear as small, grey, moist (sometimes mucoidal), and characteristically produce a zone of alpha-hemolysis (green),isolates gave positive Gram stain, negative Catalase test, negative Coagulase test, alpha hemolysis on blood agar media, Positive Bile solubility test, positive Optochin susceptibility test that show they were Streptococcus pneumoniae. 
According to sex Streptococcus pneumoniae isolated from infected male was $(31.7 \%)$, while in females was $(36 \%)$. There was a significant relationship between the occurrence of the isolates and the gender of patients $\left(\mathrm{P}^{*}=0.02\right)$.
According to age Streptococcus pneumoniae isolated in Age $\leq 35$ was $(17 \%), \quad$ in age $\geq 35$ Streptococcus pneumoniae was (37.3\%). There was a significant relationship between the occurrence of the isolates and the age of patients $\left(\mathrm{P}^{*}=0.01\right)$.

Table (1): Relation between diagnosis of cases with Gender, Age and Smoking habit:

\begin{tabular}{|c|c|c|c|c|c|c|c|c|}
\hline \multirow{2}{*}{\multicolumn{2}{|c|}{ Diagnosis }} & \multicolumn{2}{|c|}{ Gender } & \multicolumn{2}{|c|}{ Age } & \multicolumn{2}{|c|}{ Smoking habit } & \multirow{2}{*}{$\begin{array}{c}\text { Total } \\
\text { of } \\
\text { cases }\end{array}$} \\
\hline & & Male & female & $A \sigma e<35$ & $\operatorname{Age}>35$ & Non & Smokino & \\
\hline Chronic Bronchitis & $\begin{array}{l}\text { Count } \\
\%\end{array}$ & $\begin{array}{c}4 \\
9.8\end{array}$ & $\begin{array}{c}4 \\
13.33\end{array}$ & $\begin{array}{c}3 \\
25\end{array}$ & $\begin{array}{l}5 \\
8\end{array}$ & $\begin{array}{c}6 \\
15.8\end{array}$ & $\begin{array}{c}2 \\
61\end{array}$ & $\begin{array}{c}8 \\
11.27\end{array}$ \\
\hline \multirow[t]{2}{*}{ pneumonia } & Count & 13 & 10 & 6 & 17 & 15 & 8 & 23 \\
\hline & $\%$ & 31.71 & 33.33 & 50 & 29 & 39.5 & 24.2 & 32.39 \\
\hline \multirow[t]{2}{*}{ COPD } & Count & 11 & 11 & 2 & 20 & 12 & 10 & 22 \\
\hline & $\%$ & 26.83 & 36.67 & 17 & 34 & 31.5 & 30.3 & 30.98 \\
\hline \multirow[t]{2}{*}{ CSLD } & Count & 13 & 5 & 1 & 17 & 5 & 13 & 18 \\
\hline & $\%$ & 31.71 & 16.67 & 8 & 29 & 13.2 & 39.4 & 25.35 \\
\hline \multirow[t]{2}{*}{ Total } & Count & 41 & 30 & 12 & 59 & 38 & 33 & 71 \\
\hline & $\%$ & 57.7 & 42.7 & 17 & 83 & 53.52 & 46.48 & 100 \\
\hline
\end{tabular}

Chronic obstructive pulmonary disease: COPD

Chronic superlative lung disease: CSLD ((Lung abscess, Bronchiectasis))

Table (2): Relation between Streptococcus pneumoniae of cases with Gender, Age and Smoking habit of cases:

\begin{tabular}{l|l|c|c|c|c|c|c}
\hline \multirow{2}{*}{ Diagnosis } & \multicolumn{2}{c|}{ Gender } & \multicolumn{2}{c|}{ Age } & \multicolumn{2}{c}{ Smoking habit } \\
\cline { 3 - 8 } \multicolumn{2}{l|}{} & Male & Female & Age $\leq \mathbf{3 5}$ & Age $\geq \mathbf{3 5}$ & $\begin{array}{c}\text { Non } \\
\text { Smoking }\end{array}$ & Smoking \\
\hline Chronic Bronchitis & Count & 1 & 2 & 0 & 3 & 0 & 3 \\
pneumonia & $\%$ & 2.44 & 6.66 & 0 & 5.1 & 0 & 7.9 \\
& Count & 5 & 6 & 2 & 9 & 8 & 3 \\
COPD & $\%$ & 12.2 & 20 & 16.66 & 15.3 & 24.24 & 7.9 \\
& Count & 2 & 1 & 0 & 3 & 2 & 1 \\
CSLD & $\%$ & 4.9 & 3.33 & 0 & 5.1 & 6.1 & 2.6 \\
\multirow{3}{*}{ Total } & Count & 5 & 2 & 0 & 7 & 2 & 5 \\
& $\%$ & 12.2 & 6.66 & 0 & 11.9 & 6.1 & 13.2 \\
& Count & 13 & 11 & 2 & 22 & 12 & 12 \\
& $\%$ & 57.7 & 42.7 & 17 & 83 & 53.52 & 46.48 \\
\hline
\end{tabular}

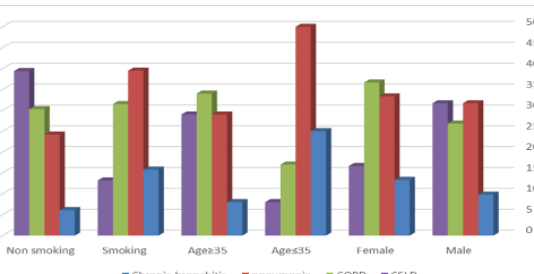

Figure (1): Relation between diagnosis of cases with Gender, Age and Smoking habit:

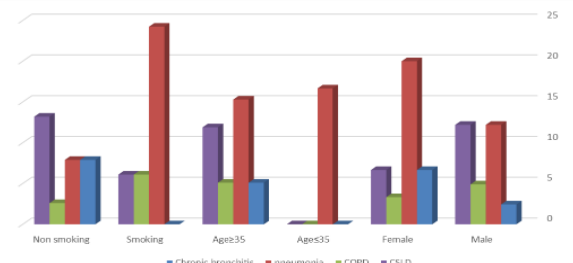

Figure (2): Relation between Streptococcus pneumoniae of cases with Gender, Age and Smoking habit of cases

Streptococcus pneumoniae isolated from patients with chronic bronchitis was $25 \%$, while pneumonia was $(50 \%)$, while chronic obstructive pulmonary disease was $14.3 \%$, and chronic suppurative lung disease was (33.8\%). (Tab.3).

Streptococcus pneumoniae isolated from nonsmoking patients was (31.58\%), while smoking patients was Streptococcus pneumoniae (36.4\%). There was no significant relationship between the occurrence of the isolates and the smoking habit of patients $\left(\mathrm{P}^{*}=0.2743\right)$.

Table (3): Relation between Streptococcus pneumoniae bacteria and diagnosis of all cases:

\begin{tabular}{c|c|c|c|c}
\hline Diagnosis & \multicolumn{2}{|c|}{$\begin{array}{c}\text { Streptococcus } \\
\text { pneumoniae } \\
\text { No }\end{array}$} & $\begin{array}{c}\text { No of } \\
\text { cases }\end{array}$ & $\begin{array}{c}\text { \% of } \\
\text { cases }\end{array}$ \\
\hline $\begin{array}{c}\text { Chronic } \\
\text { bronchitis }\end{array}$ & 3 & 25 & 12 & 16.9 \\
pneumonia & 11 & 50 & 22 & 30.99 \\
COPD & 3 & 14.3 & 21 & 29.58 \\
CSLD & 7 & 43.75 & 16 & 22.54 \\
Total & 24 & 33.8 & 71 & 100 \\
\hline
\end{tabular}




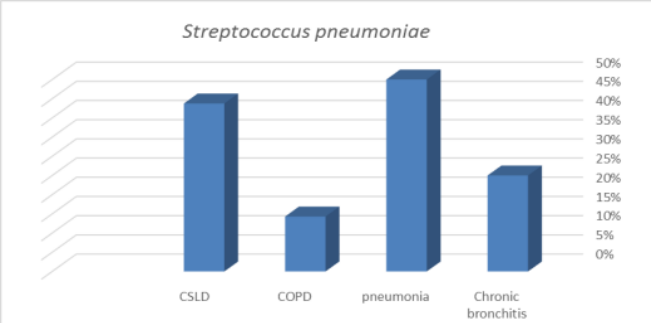

Figure (3): Relation between Streptococcus pneumoniae bacteria and diagnosis of all cases

Screening of antibiotic sensitivity of tested bacteria:

Streptococcus pneumoniae isolated was tested for their antibiotic sensitivity to fourteen different antibiotics (Levofloxacin, Azithromycin, Meropenem, Ciprofloxacin, Gentamycin, Imipenem, Cefotaxime, Cloxacillin, Ceftazidime, and Amoxicillinlclavulanic acid, Spiramycin, Piperacillin, Ampicillinlsulbactam, and Ampicillin).

Data in table show that Streptococcus pneumoniae were highly susceptible for Levofloxacin (42mm) followed by Ciprofloxacin (40mm), Meropenem (36mm), Azithromycin (34mm), Imipenem $(28 \mathrm{~mm})$, and Gentamycin (20mm) respectively S.pneumoniae resistant to Cefotaxime, Cloxacillin , Amoxicillin I clavulanic Acid, Ceftazidime, Spiramycin, Piperacillin, Ampicillin (Tab. 4).

Table (4): Antibiotic Sensitivity test of Streptococcus pneumoniae:

\begin{tabular}{|l|c|c|c|}
\hline \multicolumn{1}{|c|}{ Antibiotic } & $\begin{array}{c}\text { Abbrevia } \\
\text { tions }\end{array}$ & $\begin{array}{c}\text { Clear } \\
\text { zone }\end{array}$ & $\begin{array}{c}\text { Sensi } \\
\text { tivity }\end{array}$ \\
\hline Levofloxacin & LEV & 42 & S \\
\hline Azithromycin & AZM & 34 & S \\
\hline Meropenem & MEM & 36 & S \\
\hline Ciprofloxacin & CIP & 40 & S \\
\hline Gentamycin & GM & 20 & S \\
\hline Imipenem & IPM & 28 & S \\
\hline Cefotaxime & CTX & 0 & $\mathrm{R}$ \\
\hline Cloxacillin & OB & 0 & $\mathrm{R}$ \\
\hline $\begin{array}{l}\text { Amoxicillinlclav } \\
\text { ulanic Acid }\end{array}$ & AMC & 0 & $\mathrm{R}$ \\
\hline Ceftazidime & CAZ & 0 & $\mathrm{R}$ \\
\hline Spiramycin & SP & 0 & $\mathrm{R}$ \\
\hline Piperacillin & PIP & 0 & $\mathrm{R}$ \\
\hline $\begin{array}{l}\text { Ampecillinlsulba } \\
\text { ctam }\end{array}$ & SAM & 0 & $\mathrm{R}$ \\
\hline Ampicillin & AMP & 0 & $\mathrm{R}$ \\
\hline
\end{tabular}

S: Sensitive I: Intermediate R: Resistant

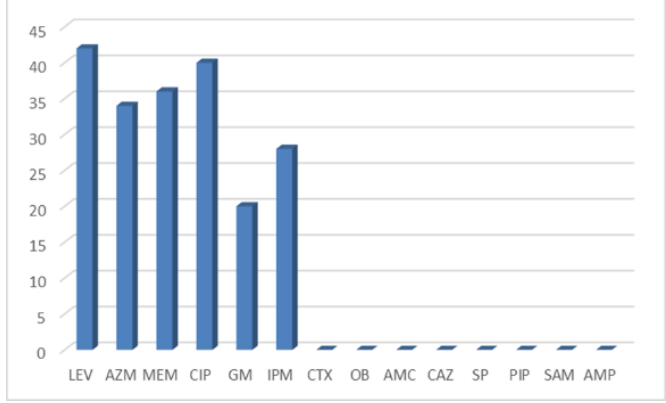

Figure (4): Sensitivity test of Streptococcus pneumoniae

\section{Discussion:}

Respiratory tract infections are the most frequently reported of all human infections. According to recent WHO report on the epidemiology of top ten infectious diseases, Lower respiratory tract infection tops the list in the developing countries and it becomes fourth in developed countries. Ndip et al., (2008). In this study the occurrence of bacterial pathogens varies with age, in that, age group more than 35 year $83 \%$ more infected than below 35 years $17 \%$. Nearly similar result were reported by Goto H, Iwasaki M. (2007), Goto H, Kumagai S. (2008), Goto H, Kumagai S.(2009), Goto H, Iwasaki M. (2010), Goto H, Iwasaki M. (2011)Found that the majority number $(57.7 \%)$ of the patients with respiratory infection were aged 70 years or older, while Salman khan, et al (2013) find out that Age group of 1-10 years old was at a higher risk .

This study found that among smoking habit Nonsmoking people 53.52\% are more infected than smoking people 46.48\%. Marcy TW etal, (1989) investigated that Cigarette smoking alters the respiratory tract ability to defend itself from 110 infection. Some subjects with chronic bronchitis have colonization of the lower respiratory tract with bacteria. Both patients with chronic respiratory disease and healthy smokers appear to have a higher frequency of respiratory infections and an increased severity of symptoms when infected. Children exposed passively to cigarette smoke have higher rates of respiratory illnesses, Lidia Arcavi, etal. (2004) found that cigarette smoking appears to be a major risk factor for respiratory tract and other systemic 
infections. Both active and passive cigarette smoke exposure increase the risk of infections, and Kozielski J (2008) show that Tobacco smoke exposure leads to development of structural and immunological changes in the lungs, these changes favor development on inflammation in the respiratory tract. Cigarette smoking is a substantial risk factor for important bacterial and viral infections.

This study found that commonest respiratory tract infection was Bacterial pneumonia (32.39\%) followed by Chronic obstructive pulmonary disease (COPD) (30.39\%), Chronic suppurative lung disease (CSLD) (25.35\%) and chronic bronchitis (11.27\%). The commonest respiratory tract infections in Man were Pneumonia (31.71\%), Chronic suppurative lung disease (CSLD) $(31.71 \%)$ followed by Chronic obstructive lung disease (COPD) (26.83\%) and chronic bronchitis (9.8\%) .While in woman are Chronic obstructive lung disease (COPD) (36.67\%), followed by Pneumonia (33.33\%), Chronic suppurative lung disease CSLD (16.67\%), and chronic bronchitis (13.33\%) . The commonest respiratory tract infections in Age $\leq 35$ are Pneumonia (50\%), followed by chronic bronchitis (25\%), Chronic obstructive lung disease (COPD) (17\%) and Chronic suppurative lung disease (CSLD) (8\%). While Age $\geq 35$ are chronic obstructive lung disease (COPD) (34\%), followed by Pneumonia (29\%), chronic suppurative lung disease CSLD (29\%) and chronic bronchitis $(8 \%)$.

According to data in [Tab. 1] The commonest respiratory tract infections in Nonsmoking people was pneumonia (39.5\%) followed by Chronic obstructive lung disease (COPD) (31.5\%), chronic bronchitis $(15.8 \%)$ and Chronic suppurative lung disease (CSLD) (13.2\%), While Smoking people was Chronic suppurative lung disease (CSLD) (39.4\%), followed by COPD $30.3 \%$, Pneumonia (24.8\%) and chronic bronchitis (6.1\%).

In this study common Bacteria causing respiratory tract infections were Streptococcus pneumoniae (34\%), nearly similar results investigated by Taura, et al .(2013) who reported that common Bacteria causing respiratory tract infections are
S.pneumoniae $25.6 \%$, A number of investigators, Goto et al (2005) reported that common Bacteria causing respiratory tract infections were Streptococcus pneumoniae, followed by Staphylococcus aureus, ,Haemophilus influenzae, Pseudomonas aeruginosa, Klebsiella pneumoniae, and Moraxella subgenus Branhamella catarrhalis, Goto H, Iwasaki $(2007,2010,2011)$ find out that common Bacteria causing respiratory tract infections were Staphylococcus aureus, Streptococcus pneumoniae, Haemophilus influenzae ,Pseudomonas aeruginosa, Klebsiella pneumoniae, and Moraxella catarrhalis. Goto, Kumagai (2008, 2009) find out that common Bacteria causing respiratory tract infections were: Staphylococcus aureus, Streptococcus pneumoniae, Haemophilus influenzae, Pseudomonas aeruginosa, Klebsiella pneumoniae, and Moraxella catarrhalis. Ndip et al.2008 find out the common Bacteria causing lower respiratory tract infections are Pseudomonas aeruginosa, followed by Haemophilus influenzae, Klebsiella pneumoniae, Streptococcus pneumoniae, Staphylococcus aureus and Escherichia coli.

Salman khan, et al (2013) demonstrated that Gram-negative bacteria were more than gram-positive bacteria. Respectively P.aeruginosa and S.pneumoniae were the most common Gram negative and Gram positive bacterial isolates recovered from lower respiratory tract infections. Asati Rakesh Kumar (2013) found out that Staphylococcus aureus (36.7\%) accounted most common organism and Klebsiella pneumonia (21.1\%) accounted second most common organism. Other organisms were Pseudomonas spp. (18.3\%), Escherichia coli (12.7\%), Staphylococcus aureus (9.8\%) and Proteus spp. (1.4\%).

This study found that Men 58\% reported respiratory tract infections more frequently than women $42 \%$. This result agree with other studies conducted by Panda et al., (2012) whose reported that, out of the 101 isolated organisms, 64 (63.4\%) were from males while 37 (36.6\%) were from females and Matthew (2007) reported that most Respiratory Tract Infections (RTIs ) is more severe in males than in females, However, these results contradicts the data obtained by $\boldsymbol{E l}$ - 
Mahmood et al., (2010), in which in a similar study, out of 232 total isolates, 114 $(49.1 \%)$ were from males while 118 $(50.9 \%)$ from females. In this study the commonest Bacteria in infected male is Streptococcus pneumoniae (31.7\%) and in females are S.pneumoniae, $(36 \%)$

The commonest Bacteria isolated in age $\geq$ 35 is Streptococcus pneumoniae, Panda et al., (2012), recorded higher occurrence of $K$. pneumoniae among patients ranging from 51-60 and 60-70 years. and $\boldsymbol{D}$. $\boldsymbol{W}$. Taura,et al .(2013) find out that Age ranges $20-29$ and $30-39$ have the highest percentage of pathogens isolated.

Streptococcus pneumoniae is the commonest Bacteria isolated from non smoking and smoking patients (31.58\%), (36.4\%) respectively.

In this study the commonest bacteria isolated from patients with pneumonia was Streptococcus pneumoniae (50\%) This result agree with Goto H; et al (2005)who investigated that the commonest bacteria frequently isolated from the patients with bacterial pneumonia were Streptococcus pneumoniae $(23.4 \%)$, on the other hand, Goto H, Iwasaki M. (2007) find out that the commonest bacteria frequently isolated from the patients with bacterial pneumonia were Staphylococcus aureus (21.9\%) .In this study Streptococcus pneumoniae isolated from $25 \%$ of patients infected with chronic bronchitis, $3 \%$ of patients infected with COPD, $7 \%$ of patients infected with CSLD.

In this study Streptococcus pneumoniae highly susceptible for Levofloxacin followed by Ciprofloxacin, Meropenem, Azithromycin, Imipenem, and Gentamycin respectively S.pneumoniae resistant to Cefotaxime, Cloxacillin, Amoxicillinlclavulanic Acid, Ceftazidime, Spiramycin, Piperacillin, Ampecillinl sulbactam, Ampicillin. [Tab. 4]. Number of investigators, Rosa del Campo, etal (2005) investigated that Forty-eight Streptococcus pneumoniae isolates recovered from sputum samples High over all resistance rates were observed: to penicillin, 73\%; to Cefotaxime, 33\%; to erythromycin, $42 \%$; to tetracycline, $58 \%$; to chloramphenicol, $48 \%$; and to trimethoprim-sulfamethoxazole, $\quad 67 \%$. Resistance to fluoroquinolones was not detected. Multi resistance was a common feature (60\%), Iroha Ifeanyichukwu Romanus, etal (2013) found out that Streptococcus spp. were susceptible to ciprofloxacin, Ceftazidime and amikacin but resistant to amoxicillin/clavulanic acid, and ampicillin.

\section{References}

Archer GL and Ronald PE, 2001. "Treatment and prophylaxis of bacterial infections". Harrison's Principle. Inter. Med., 15: 867881.

Asati Rakesh Kumar,(2013) : " Antimicrobial sensitivity pattern of Klebsiella pneumonia isolated from pus from tertiary care hospital and issues related to the rational selection of antimicrobials". Journal of Chemical and Pharmaceutical Research, 2013, 5(11):326331.

Barie PS, 1998. "Antibiotic-resistant grampositive cocci implications for surgical practice". World J. Surg., 22(2): 118-126.

Carla A. Talarico .(2009):Epidemiologic Characteristics of Colonizing Streptococcus pneumoniae in Vietnam and Implications for Population Vaccination.

Cheesbrough M.(2000). "Microbiological tests in Chees brough ,M.(ed.)District Laboratory practice in Tropical countries". Cambridge university Press,U.K.;1-266.

Conte JE, 2002. " Manual of antibiotics and infectious diseases; treatment and prevention". Lippincott Williams and Wilkins, Philadelphia, 9th ed., pp. 381-385.

Cowan SJ, Steel KJ (1974). Cowan and Steel manual for identification of medical bacteria, 2nd edn Cambridge University Press, London. pp. 176-232.

Cowan SJ, Steel KJ (1974). Cowan and Steel manual for identification of medical bacteria, 2nd edn Cambridge University Press, London. pp. 176-232

Domin MA, 1998. Highly virulent pathogens; a post antibiotic era? Br. J. Theatr. Nurs. 2: 14-28.

El-Mahmood AM, Isa H, Mohammed A, Tirmidhi AB (2010): Antimicrobial susceptibility of some respiratory tract pathogens tocommonly used antibiotics at the specialist hospital, Yola,Adamawa, Nigeria. J. Clin. Med. Res. 2(8), 135-142.

Goto H, Iwasaki M. (2011): "Susceptibilities of bacteria isolated from patients with lower respiratory infectious diseases to antibacterial agents" .Jpn J Antibiot. 2015 Apr; 68(2):105-24. 
Goto H, Iwasaki M.(2007):"Susceptibilities of bacteria isolated from patients with lower respiratory infectious diseases to antibacterial agents . Jpn J Antibiot. 2015 Feb;68(1):1-18.

Goto H, Iwasaki M.(2010) : Susceptibilities of bacteria isolated from patients with lower respiratory infectious diseases to antibacterial agents. Jpn J Antibiot. 2015 Apr;68(2):85-104.

Goto H, Kumagai S. (2008): Susceptibilities of bacteria isolated from patients with lower respiratory infectious diseases to antibacterial agents . Jpn J Antibiot. 2015 Feb;68(1):19-36.

Goto H, Kumagai S. (2009): "Susceptibilities of bacteria isolated from patients with lower respiratory infectious diseases to antibacterial agents". Jpn J Antibiot. 2015 Feb; 68(1):37-54.

Goto H; Takeda H,Kawai S,Watanabe S ,Okazaki M,Shimada K ,Nakano K ,Yokouchi H ,Mori T ,Igari J ,Oguri T ,Yamamoto M ,Kudo K ,Kobayashi N ,Tanaka T ,Yoshimura K ,Kawabata M ,Nakamori Y, Sumitomo M, Inoue H ,Nakadate T ,Suwabe A, Ashino Y ,Aoki N ,Honma Y ,Suzuki Y ,Karasawa Y ,Oka M ,Kobashi Y Kohno S ,Hirakata Y ,Kondou A, Matsuda J ,Nakano M,Oikawa S (2005): "Susceptibilities of bacteria isolated from patients with lower respiratory infectious diseasesto antibiotics " Jpn J Antibiot Aug; Vol. 61 (4), pp. 209-40.

Holt ,J.G.;Krieg,N.; Sneath, P.H.;Staley, J.T.; Williams,T. and Hensyl, W.R(1994): Bergy's manual of determinative bacteriology 9th ed., Williams and Wilkins, Baltimore, Meryland.

Iroha Ifeanyichukwu Romanus, Nwakeze Amobi Emmanuel, Afiukwa Felicitas Ngozi, Udu-Ibiam Esther Onyinyechi, Nwuzo Agabus Chidiebube, Oji Anthonia Egwu and Ngwu Tina Nnenna (2013): "Antibiotic susceptibility patterns of bacterial isolates from hospitalized patients in Abakaliki" International Research Journal of Basic and Clinical Studies Vol. 1(4) pp. 46-52, April 2013

Kozielski J (2008) :[Smoking and lung infection] Pneumonol AlergolPol. 2008; 76(4):271-5.

Levin AS and Levy CE, 2003. Severe nosocomial infections with imipenemresistant Acinetobacter baumannii treated with ampicillin/sulbactam. Int. J. Antimicrob. Agents, 21(1): 58-62
Lidia Arcavi, MD; Neal L. Benowitz, MD (2004) "Cigarette Smoking and Infection" Arch Intern Med. 2004;164(20):2206-2216. doi:10.1001/archinte.164.20.2206.

Lynch JP 3rd, Zhanel GG. (2010): Streptococcus pneumoniae: epidemiology and risk factors, evolution of antimicrobial resistance, and impact of vaccines. Curr Opin Pulm Med. 2010 May; 16(3):217-25. doi: 10.1097/MCP.0b013e3283385653.

Marcy TW, Merrill WW.(1989)"Cigarette smoking and respiratory tract infection". Clin Chest Med. 1987 Sep;8(3):381-91.

Ndip RN, Ntiege EA, Ndip LM, Nkwelang G, AoachereTK, Nkuo Akenji.(2008). Antimicrobial resistance of bacterial agents of the upper respiratory tract of school children in Buea, Cameroon. J Health Population and Nutrition; 26: 397-404.

Panda SB, Nadini P, Ramani TV (2012). Lower respiratory tract infection Bacteriological profile and antibiogram pattern. Int. J. Cur.Res. Rev. 04(21): 149-155.

Perez C, Paul M and Bezique P, 1990. An Antibiotic assay by the agar well diffusion method. Alta. Biomed. Group. Exper. 15: 113-115.

Petrosillo N and Pantosti A, 2002. Prevalence, determinants, and molecular epidemiology of Streptococcus pneumoniae isolates colonizing the nasopharynx of healthy children in Rome. Eur. J. Clin. Microbiol. Infect. Dis., 21(3): 181-188.

Rosa del Campo, María-Isabel Morosini,Elia Gómez-G. de la Pedrosa,1 Asunción Fenoll,2 Carmen Muñoz-Almagro, Luis Máiz,1 Fernando Baquero,Rafael Cantón(2005):" Population Structure, Antimicrobial Resistance, and Mutation Frequencies of Streptococcus pneumoniae Isolates from Cystic Fibrosis Patients".J Clin Microbiol. 2005 May; 43(5): 22072214.

Salman Khan, Priti Singh, Mukhtar Ansari, Kishor Gurung (2013): Bacteria Etiological Agents Causing Lower Respiratory Tract Infections in the Western Part of Nepal. Ibnosina Journal of Medicine and Biomedical Sciences.

Taura D. W., A. Hassan, A. M. Yayo and H. Takalmawa (2013): "Bacterial isolates of the respiratory tract infection and their current sensitivity pattern among patient sattending Aminu Kano Teaching Hospital Kano-Nigeria" International Research Journal of Microbiology (IRJM) (ISSN: 2141-5463) Vol. 4(9) pp. 226-231, October, 2013. 
عنوان البحث: الاراسات الوبائية على العلاقة بين بكتريا Streptococcus pneumoniae وأمراض الجهاز التنفسي

أحمد اسماعيل عبدالقادر1 ومجدي محسن بهجت1 ومحمد عبدالرعوف العاملي2 مني عبدالرعوف عبدالله مفتاح11 1 ملية الطلوم - جامعة بورسعيد 1 ملية الطب - جامعة المنصورة

تعتبر بكتريا Streptococcus pneumoniae السبب الرئيسي للعدوى البكتيرية في جميع أنحاء العالم وتسبب

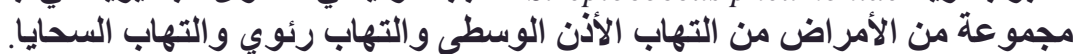

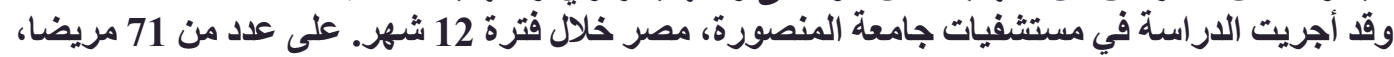

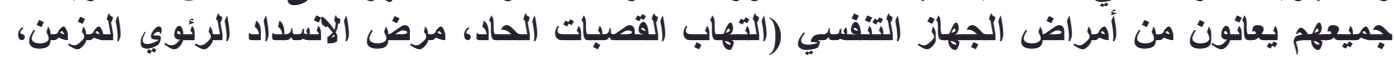

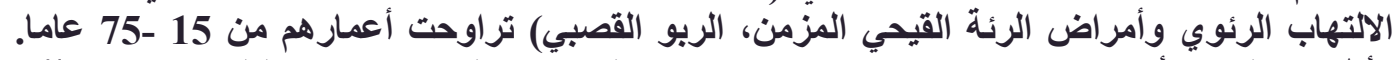

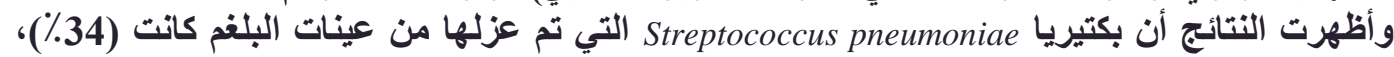
Streptococcus pneumoniae

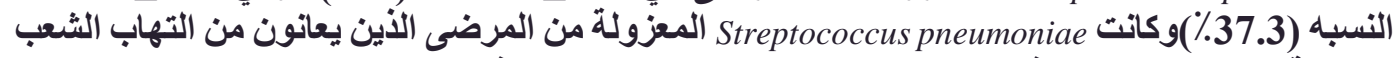

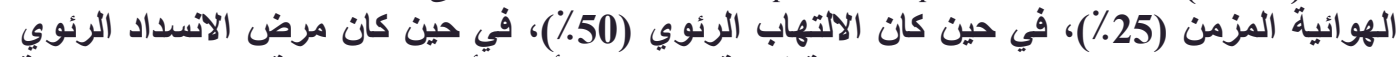

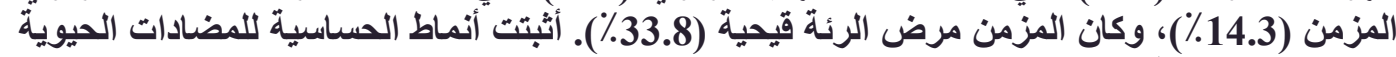
ان البكتريا حساسة جال الليفوفلوكساسين. 